\title{
Evaluation of a Simple, Inexpensive Dialysis Sampler for Small Diameter Monitoring Wells
}

\author{
by Thomas Harter and Samer Talozi
}

\begin{abstract}
We developed and tested a simple, inexpensive dialysis sampler design for in situ measurement of nitrate and salinity in monitoring wells. The dialysis sampler is made with regenerated cellulose membrane tubing that is placed in an open cage, 18.5 $\mathrm{mm}$ in diameter and constructed of commonly available, inexpensive hardware. The design was tested in a monitoring well network installed in shallow, relatively warm $\left(21^{\circ} \mathrm{C}\right)$ ground water of a sandy aquifer impacted by animal waste discharge and agricultural fertilizer. Three dialysis samplers were placed near the bottom, center, and below the top of $7 \mathrm{~m}$ long well screens in an otherwise open well casing (open multilevel sampling [oMLS]). In laboratory tests we found that 1 to $4 \mathrm{~d}$ was sufficient equilibration time to collect a representative sample, yet short enough to ensure the integrity of the membrane samplers, which began to degrade after $\sim 1$ week. Significant, density-stable salinity gradients were detected in $\sim 25 \%$ of samples taken on two sampling dates in 40 wells. Nonuniform, heterogeneous nitrate profiles were much more common $(80 \%)$. Despite the nonuniformity in the open profile, the average of the three samplers (= composite sample) was generally within $10 \%$ of the electrical conductivity and nitrate concentrations obtained by standard purging and well sampling using a pump. At initial hardware costs of approximately $\$ 1$ per reusable oMLS sampling string and at sampling costs of $\$ 1$ to $\$ 3$ per oMLS sampling string for disposable membrane material, dialysis samplers are a good candidate for a low-cost, low-tech sampling device to determine major water quality parameters in small diameter ground water monitoring wells.
\end{abstract}

\section{Introduction}

In situ monitoring of ground water with dialysis samplers is a well-established ground water monitoring technique, particularly for measuring ground water quality profiles in multilevel sampling wells (Ronen et al. 1986; Dasika and Atwater 1995). Sampling by dialysis is the most common of three in situ chemical fractionation methods to monitor water quality by passive sampling, and the only one of these methods used in ground water studies (Davison et al. 2000). Dialysis samplers are based on the principle of diffusional equilibration. That is, a small (few milliliters to few tens of milliliters) sampling vial or sampling bag with a semipermeable membrane lid or wall is filled with a sampling medium (in ground water applications, this is typically deionized water). This is also referred to as the sequestering phase. The sampler is deployed in an aqueous environment (e.g., well), where passive diffusion through the semipermeable membrane allows the water quality in the sampling medium to

Received June 2003, accepted M arch 2004.

Copyright (C)2004 by the National Ground Water Association. equilibrate with that in the surrounding aqueous environment over the course of a few hours, days, or weeks. Both polar membranes, such as regenerated cellulose and nonpolar membranes (Tygon $^{\circledR}$, Teflon ${ }^{\circledR}$, cellulose acetate, polycarbonate, polysulfone, polyethylene, polypropylene, and others) are used. The type of membrane determines which solutes pass into the sampling medium. Polar membranes are suitable for sampling common ionic solutes in ground water, as well as organic solutes with relatively low molecular weight. Nonpolar dialysis membrane samplers are primarily used for monitoring organic contaminants, dissolved gases, and volatile organic carbons (VOCs). Instead of aqueous solutions, some applications use organic solvents in the sequestering phase to monitor, for example, environmental organic contaminant uptake in marine and aquatic organisms (Södergren 1987; Prest et al. 1995; Chapman 2000).

Dialysis samplers are also referred to as passive diffusion samplers (Divine and McCray 2004), passive diffusion bag samplers (Vroblesky and Hyde 1997; Vroblesky 2001), semipermeable membrane devices (Prest et al. 1995; Chapman 2000), or simply as passive samplers. Diffusive equilibration in thin films (DET) is a similar method to dialysis samplers. The term is used for samplers with a hydrogel thin film rather than a solution as the sampling medium. Diffusive gradients in thin films (DGT), which also use a hydrogel, 
do not rely on equilibrium, but rather separate chemical species kinetically onto a binding layer underneath the hydrogel (Davison et al. 2000). DET and DGT have, to our knowledge, not been used in ground water applications.

Although dialysis samplers are very common, such as for sediment pore water monitoring (Hesslein 1976; Peiffer et al. 1999; Davison et al. 2000), few publications exist that describe the use of dialysis samplers in ground water studies. An excellent and uniquely exhaustive review of in situ dialysis, DET, and DGT sampling techniques by Davison et al. (2000) listed only six publications describing methods and applications of the dialysis technique in ground water (Dasika and Atwater 1995; Kaplan et al. 1991; Rettinger et al. 1991; Ronen et al. 1986; Ronen et al. 1987; Weisbrod et al. 1996). Recently, low density polypropylene (LDPE) dialysis samplers have been extensively tested for monitoring VOC contamination in ground water and surface water (Vroblesky and Hyde 1997; Vroblesky 2001; U.S. Air Force 2003). The Interstate Technology Regulatory Council (ITRC) maintains a Web-based information center on dialysis samplers (there called diffusion samplers), which focuses primarily on the use of LDPE samplers (www.itrcweb.org). The lack of more studies that describe the use of cellulosebased dialysis samplers for monitoring dissolved inorganic constituents in ground water encouraged us to share our experiences with a modest but potentially very useful protocol for ambient ground water monitoring studies.

Dialysis samplers have several advantages over other ground water sampling methods. (1) They do not require the removal (and disposal) of large amounts of well water prior to sampling. (2) They measure water quality under natural conditions without external forcing (passive sampling). (3) They can be used to sample water quality with a high degree of spatial resolution, hence their primary use in multilevel ground water samplers.

A fourth and not unimportant advantage is the potential ease of use and the low expense of the sampling equipment. A simple sampler design can be quickly assembled in a modestly equipped workshop from materials that are readily available in a hardware store. Ease of use and low cost are critical, as small diameter monitoring wells (with no permanent pumps installed) become more common not only at industrial contamination sites administered by professional consultants, but also among some homeowners affected by ground water pollution, and especially among farmers responsible for monitoring agrochemical residues, particularly nitrate, in shallow ground water. In developing countries, these samplers may provide a low-cost alternative to other ground water monitoring techniques.

A key concern in the use of dialysis samplers is the time needed for equilibration between ambient ground water quality, ground water quality in the well, and solute concentration in the sampling device (Divine and McCray 2004). In our case, the deployment of the dialysis sampler was also limited due to relatively warm ground water $\left(21^{\circ} \mathrm{C}\right)$ and potentially significant microbial activity from waste water discharge into ground water. High temperature and the presence of microbes are known to significantly shorten the longevity of the regenerated cellulose membranes (Dasika and Atwater 1995). Few data exist that evaluate the field performance of the cellulose membrane dialysis sampler, especially for use in relatively warm, shallow ground water with potentially elevated salinity and elevated microbial activity.

The goal of our work is fourfold. First is to develop a design for an inexpensive, robust, and homemade small diameter monitoring well sampling technique that can measure salinity and nitrate concentrations in monitoring wells. Second is to establish the necessary equilibration time and test the accuracy of the sampler for nitrate and salinity monitoring under laboratory conditions. Third is to investigate the performance of these samplers under field conditions, particularly when potentially significant concentration gradients exist along the screened interval of a monitoring well. And fourth, to apply them to study nitrate and salinity profiles in 2.5 and $5.1 \mathrm{~cm}$ ground water monitoring wells completed in the top $7 \mathrm{~m}$ of a sandy alluvial aquifer that has been impacted by fertilizer and animal waste applications. Nitrate and salinity are of specific concern, since these are the most widespread ground water pollutants (U.S. Geological Survey 1999).

\section{Methods}

\section{Simple Dialysis Membrane Sampler Design}

The simple dialysis membrane sampler consists of a small diameter, regenerated cellulose-based dialysis membrane bag (referred to as "sausage" by Dasika and Atwater [1995]) that is inserted into a protective, open cage. The following provides details of the design and preparation protocol.

Dialysis membrane bags were prepared from a $30 \mathrm{~m}$ role of regenerated cellulose membrane tubing readily available from scientific/medical supply catalogues or directly from the manufacturer (Spectra/Por 1 tubing with 6000 to 8000 Dalton MWCO, Spectrum Laboratories, Rancho Dominga, California). The membrane has a nominal pore size of $18 \AA$ and a nominal wall thickness of $50 \mu \mathrm{m}$ (wetted). For applications in 2.5 and $5.1 \mathrm{~cm}$ diameter monitoring wells, we used $14.6 \mathrm{~mm}$ diameter membrane tubing (larger diameter tubing is also available), which holds $1.7 \mathrm{~mL} / \mathrm{cm}$ of tubing. Individual bags were prepared and handled using latex gloves. Sections, $30 \mathrm{~cm}$ each, were cut from the membrane tubing, then washed and triple-rinsed in deionized water to remove glycerol and sulfides, which are used as plasticizer and for tubing preservation (precleaned membrane tubing is available from some manufacturers). The clean tubing was filled with deionized water and tie-sealed at both ends using nylon or ePTFE tape (dental floss). The dialysis membrane bag contained $\sim 47 \mathrm{~mL}$ of water. The bags were suspended in a 18.5 $\mathrm{mm}$ diameter, $30 \mathrm{~cm}$ long cage to protect the membrane bag against scraping along the monitoring well casing, to protect it against surface contamination during the placement and extraction of the sampler, and to provide a weight. The cages were built using three $32 \mathrm{~cm}$ threaded steel rods, two 18.5 $\mathrm{mm}$ washers with three predrilled holes in each, and 12 zinc nuts to tie the washers in place at the top and bottom of the three rod sections (Figure 1). After the dialysis membrane bags were prepared in the lab on the day of use, they were stored in a cooled amber container filled with deionized water. For deployment, the bags were tied into the cages 


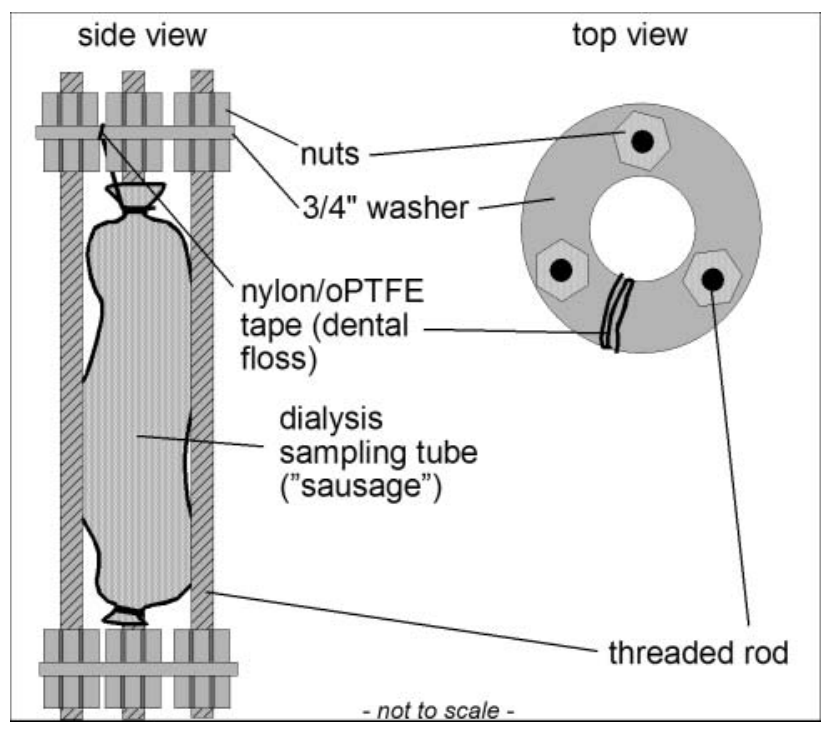

Figure 1. Schematic diagram (not to scale) illustrating the design of our cage dialysis sampler. Three cages are strung in series using inert nylon tape and are lowered into a small diameter monitoring well.

using ePTFE tape. The complete assembly of a dialysis membrane bag in a cage is subsequently referred to as the dialysis sampler.

At the end of the predetermined equilibration period (subsequently described), the dialysis samplers were pulled from the well (or, in the case of the laboratory studies, from the well simulation container). The dialysis membrane bags were removed from the cages and carefully shaken to remove any water on the outside of the membrane. At one end of the bag, water was pressed away and the bag carefully clipped with scissors, a procedure also tested by Ehlke et al. (2004) in conjunction with VOC sampling. The sample water was then gently pressed out of the bag into a sample bottle. Sample bottles were cooled and stored at $4^{\circ} \mathrm{C}$ until analysis. Samples were analyzed for $\mathrm{NO}_{3}-\mathrm{N}$ using the diffusion-conductivity analyzer (Carlson 1978). The method has a detection limit of $\sim 0.05 \mathrm{mg} / \mathrm{L}$ with a precision of better than $1 \%$ relative percent deviation. Electric conductivity (salinity) was measured with a conductivity meter (detection limit of $0.01 \mathrm{mmhos} / \mathrm{cm}$, generally reproducible within $7 \%$ ).

\section{Laboratory Test 1}

A laboratory test was conducted to evaluate the accuracy of the dialysis sampler and to determine the appropriate equilibration period under relatively warm ambient temperature conditions. A $150 \mathrm{~L}$ amber polypropylene container was filled with $115 \mathrm{~L}$ of water pumped from one of the monitoring wells used in the field study (test solution). The container was stored at $21^{\circ} \mathrm{C}$, the in situ ground water temperature of the field experiment. The $21^{\circ} \mathrm{C}$ temperature was maintained throughout the experiment. Twelve dialysis samplers were suspended vertically in the test solution and the container was sealed (no air circulation and no light). Two to three times per day, the test solution in the container was gently stirred to allow for good mixing and uniform equilibration among the membrane samplers. A set of three dialysis samplers was removed after each of the following equilibration times-24, 72, 96, and $168 \mathrm{~h}$. Immediately before the initial placement of the samplers on day 0 and immediately after removing each set, the test solution in the container was mixed and two separate $60 \mathrm{~mL}$ test solution samples were collected. All samples were cooled and stored at $4^{\circ} \mathrm{C}$ until analysis.

\section{Laboratory Test 2}

To test the sampling procedure over a wide range of nitrate concentrations, a simplified version of laboratory test 1 was repeated for ground water from four different monitoring wells, each with different nitrate concentrations. In this test, ground water (test solution) from each of four wells was split into three $200 \mathrm{~mL}$ amber polypropylene container bottles (three replicates per well). One dialysis sampler was placed in each bottle, and the bottles were sealed and stored at $21^{\circ} \mathrm{C}$ for $4 \mathrm{~d}$ with occasional stirring. Immediately prior to the initial sampler placement and immediately after removing the samplers on the last day, the test solution in each bottle was stirred and a representative sample collected. All samples were cooled and stored at $4^{\circ} \mathrm{C}$ until analysis. Test 2 samples were analyzed for $\mathrm{NO}_{3}-\mathrm{N}$ only.

\section{Field Sampling}

The field experiment was conducted in a monitoring well network consisting of 2.5 and $5.2 \mathrm{~cm}$ PVC monitoring wells. The wells were constructed to $\sim 9 \mathrm{~m}$ depth and screened from $\sim 2.4$ to $\sim 8.4 \mathrm{~m}$ (exact screen intervals vary by up to $0.9 \mathrm{~m}$ among wells). Depth to water table was variable and ranged from 2 to $4 \mathrm{~m}$. The shallow alluvial aquifer material consisted predominantly of fine sand with intercalated sandy loam and loam. The estimated hydraulic conductivity was $18 \mathrm{~m} / \mathrm{d}$ (Harter et al. 2002). Depending on location, water quality in the monitoring wells was variably affected by irrigation and commercial fertilization of corn and small grain crops, by cattle manure amendments (liquid and solid) to field crops, by manure deposition in feedlots, by septic tank leach fields, or by leaching from liquid manure storage basins (Harter et al. 2002).

We used a simple, open multilevel sampling (oMLS) configuration to define the average nitrate and salinity concentration across the screened interval of the monitoring well, and to study the vertical nitrate and salinity distribution within the fully screened section of the monitoring well (the top $\sim 4.5$ to $6 \mathrm{~m}$ of the aquifer). In contrast to Dasika and Atwater (1995), Ronen et al. (1986), and Ronen et al. (1991), we did not use spacers that prevented water circulation inside the well casing. Hence, our design did not require the preassembly of a long, rigid tool string for insertion into the well. Instead, three dialysis samplers were hung in series using a single string of nylon or ePTFE tape. They were placed at depths of $0.6,2.7$, and $4.8 \mathrm{~m}$ below the water table $(\sim 3,5.1$, and $7.2 \mathrm{~m}$ below ground surface). The oMLS sampling string was slowly inserted into the well to minimize perturbations in the water column inside the monitoring well. After an equilibration time of $4 \mathrm{~d}$, the oMLS sampling string was quickly removed from the well and sampled according to the aforementioned protocol. A total of 43 wells were sampled in the early fall, after completion of the irrigation season; 40 of these 43 wells were resampled nine months later during the middle of the following irrigation season. 
Each oMLS field sampling occurred 4 weeks after the last and immediately prior to the next scheduled regular monitoring well sampling. Regular well sampling was performed using a peristaltic pump in the $2.5 \mathrm{~cm}$ wells and a variable-speed submersible pump in the $5.1 \mathrm{~cm}$ wells. For the regular sampling, $\sim 5$ to 10 well volumes of water were removed prior to sampling, which provided a thoroughly mixed sample of formation water. Pumps are placed in the center of the screened section; however, pump depth location (top, center, or bottom) and purging volume (10 to 1000 well volumes) have been shown to have negligible impact on water quality (Harter et al. 2002). Estimated ground water pore velocities are in excess of $10 \mathrm{~cm} / \mathrm{d}$ (Harter et al. 2002). A four week period between regular sampling and oMLS testing was therefore considered more than sufficient time to allow for natural gradient and solute stratification conditions to return to the aquifer immediately around and the well. The oMLS test was also scheduled to occur during a period with minimal impact on the water level or solute concentration from nearby field irrigations, nearby pumping, or from precipitation. Within $2 \mathrm{~d}$ after the oMLS sampling completion, a regular ground water sample was obtained for comparison to the oMLS samples. Again, no precipitation or nearby irrigations occurred during those days.

\section{Results and Discussion}

\section{Laboratory Testing}

For both test solution and dialysis sampler samples, the coefficient of variation among experiment 1 replicates of electrical conductivity (EC) and $\mathrm{NO}_{3}-\mathrm{N}$ measurements was $<1 \%$, resulting in narrow confidence intervals. An exception are early test solution EC samples on days 0,1 , and 3 (Figure 2, top). Differences between dialysis sampler $\mathrm{NO}_{3}-\mathrm{N}$ and test solution $\mathrm{NO}_{3}-\mathrm{N}$ were significant, albeit small (4\% to $5 \%$ ). Differences in $\mathrm{NO}_{3}-\mathrm{N}$ persisted over the $7 \mathrm{~d}$ exposure period (Figure 2, center), while sampler EC asymptotically reached test solution $\mathrm{EC}$ after $4 \mathrm{~d}(<1 \%$ difference). In other test solutions (experiment 2), differences between the average of the replicate test solution and the replicate membrane sample concentrations were equally small or smaller $(0.3 \%$ to $4 \%$ ) with membrane sample concentrations consistently above those observed in the test solution samples (Figure 2, bottom). Overall, it appeared that near-equilibrium conditions were achieved in $<1 \mathrm{~d}$. An exposure time of 3 to $4 \mathrm{~d}$ was therefore considered sufficient to obtain a sample that is within $5 \%$ of the ambient $\mathrm{EC}$ and $\mathrm{NO}_{3}-\mathrm{N}$ concentration. We use the additional equilibration time after day 1 primarily to assure that any mixing effects in the well from the initial placement of the samplers are reverted to natural conditions.

An equilibration period of $\sim 1 \mathrm{~d}$ to a few days is consistent with findings in previous experimental work on the performance of regenerated cellulose membrane samplers (Harper et al. 1997; Davison et al. 2000; Ehlke et al. 2004). Equilibration times vary with the size and shape of the sampler, the solute of interest, and the semipermeable membrane material. For applications in wells with small diameter dialysis membrane samplers, it is reasonable to assume sustained mixing of the solution around the dialysis sampler and good
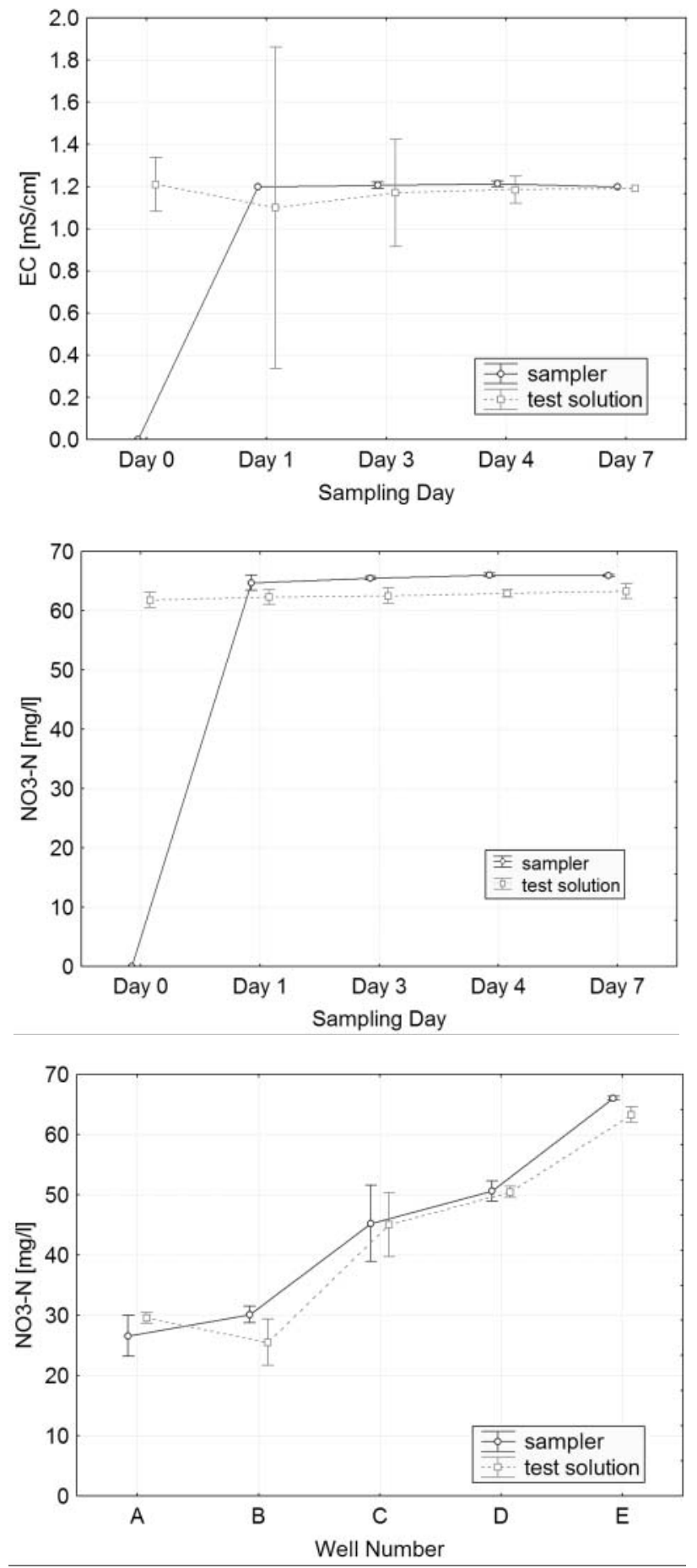

Figure 2. Test solution and dialysis sampler concentrations for $\mathrm{EC}$ (top) and $\mathrm{NO}_{3}-\mathrm{N}$ (center) over a 7d placement period using ground water from well $\mathbf{E}$ as test solution (experiment 1). At the bottom is a comparison of sampler and test solution $\mathrm{NO}_{3}-\mathrm{N}$ on day 4 after placement in test solutions obtained from wells A through E (experiment 2). Vertical bars indicate $95 \%$ confidence interval of the mean.

diffusional mixing within the sampling medium. Under those conditions, Fick's first law of diffusion has been used to estimate equilibration time in thin membrane samplers (Brandl and Hanselmann 1991; Sanford et al. 1996; Divine and McCray 2004):

$$
t=\frac{F}{k_{m}} \ln \left[\frac{C_{0}}{C_{0}-C_{t}}\right]
$$


where the design factor $F(\mathrm{~cm})$ is the ratio of sampler volume to membrane surface area; the membrane permeation coefficient $k_{m}(\mathrm{~cm} / \mathrm{s})$ is effectively the ratio of the species diffusion coefficient in the membrane, $D_{m}\left(\mathrm{~cm}^{2} / \mathrm{s}\right)$, to the thickness of the membrane, $L(\mathrm{~cm}) ; C_{0}$ is the constant concentration in the solution (i.e., ground water) around the sampler; and $C_{t}$ is the concentration in the sampling solution at time $t(\mathrm{~s})$. The solution (Equation 1) assumes that $C_{t}$ at time 0 is zero and that $F>L$ (Sanford et al. 1996). Given the estimated ground water velocity of $10 \mathrm{~cm} / \mathrm{d}$, we can assume relatively sustained mixing of solutes around the sampler. For our sausage design, the design factor, $F=0.37 \mathrm{~cm}$, is much lower than in the vial-based samplers with small membrane lids (Ronen et al. 1986; Peiffer et al. 1999) leading to shorter equilibration time and to faster diffusional mixing within the sampling medium.

Diffusion coefficients of common salts and nitrate within the regenerated cellulose membranes are not generally known and must be estimated experimentally. By rearranging Equation 1, we obtain

$$
D_{m}=\frac{F L}{t} \ln \left[\frac{C_{0}}{C_{0}-C_{t}}\right]
$$

Ehlke et al. (2004) found that equilibration times of bromide and iron were $<3 \mathrm{~d}$. Using Equation 2 and assuming 95\% equilibration, $D_{m}$ of bromide and iron is found to be at least $\sim 10^{-7} \mathrm{~cm}^{2} / \mathrm{s}$ or two orders of magnitude smaller than their diffusion coefficient in dilute aqueous solutions. Our equilibration experiments $\left(t_{95 \%}<1 \mathrm{~d}\right)$ suggest that $D_{m}$ for EC (major anions and cations) and for nitrate are also on the order of $6 \times 10^{-8}$ to $10^{-7} \mathrm{~cm}^{2} / \mathrm{s}$ (also approximately two orders of magnitude lower than the diffusion coefficient in dilute aqueous solutions). Hence, minimum equilibration times for regenerated cellulose samplers with other geometric configurations and most inorganic anions or cations can be estimated from Equation 1 by conservatively using $D_{m}=$ $5 \times 10^{-8} \mathrm{~cm}^{2} / \mathrm{s}$ and the appropriate design factor $F$.

\section{Field Testing}

Nitrate- $\mathrm{N}$ concentration in the membrane samples ranged from $<1$ to $>100 \mathrm{mg} / \mathrm{L}$. EC ranged from $<0.4$ to $>4 \mathrm{mS} / \mathrm{cm}$. Generally, there was a good agreement between the mean $\mathrm{NO}_{3}-\mathrm{N}$ and $\mathrm{EC}$ values of the three membrane samples (equivalent to a composite sample) and those of the regular well samples (Figure 3). The squared correlation coefficient between average membrane and regular sampling results was 97\% for EC (both years) and 93\% and 95\% for years 1 and 2 , respectively, in the case of $\mathrm{NO}_{3}-\mathrm{N}$ (Figure 3, which does not include four outliers). While the slope of the regressions are nearly 1:1 (Figure 3), there are significant offsets (y-axis intercept) in the regression of the EC that reflect the positive bias in the mean dialysis sampler EC values relative to the typically smaller regular sample EC values. A similar bias toward higher mean dialysis membrane values (compared to regular samples) is observed only in year 1 of the $\mathrm{NO}_{3}-\mathrm{N}$ samples. There, the y-axis intercept is small, but the regression slope is much steeper than 1 . The absolute differences between mean membrane values and regular sample values are near-exponentially distributed with a geometric mean of
$5.1 \mathrm{mg} / \mathrm{L} \mathrm{NO}_{3}-\mathrm{N}$ and $0.14 \mathrm{mS} / \mathrm{cm} \mathrm{EC}(5.4 \mathrm{mg} / \mathrm{L}$ and 0.16 $\mathrm{mS} / \mathrm{cm}$, respectively, if the four outliers are considered).

Because of the time delay and the shallow sampling location, it is plausible that small changes in concentration may have occurred over the 1 to $2 \mathrm{~d}$ period between the dialysis sampling and the regular sampling. However, changes would be uncorrelated between wells and would not produce the observed bias. In addition, changes over $2 \mathrm{~d}$ within individual wells should be relatively small $(<10 \%$ of their average value in the membrane samples).

Concentration differences between samples collected by dialysis samplers and samples obtained from pumping may also be caused by the differences in sample volumes: The pumped well samples are representative of a volume of water equal to approximately five times the volume of the screened monitoring well section. The oMLS assembly with the dialysis membrane samplers samples from a significantly smaller and discrete volume, although not as small as the sampler itself; the concentration represents an average concentration of all water that has passed the sampler during the 12 to $48 \mathrm{~h}$ period prior to sampling. The fact that nitrate- $\mathrm{N}$ samples obtained from the membrane samplers tend to be slightly higher than those obtained from ground water is consistent with the lab experiment.
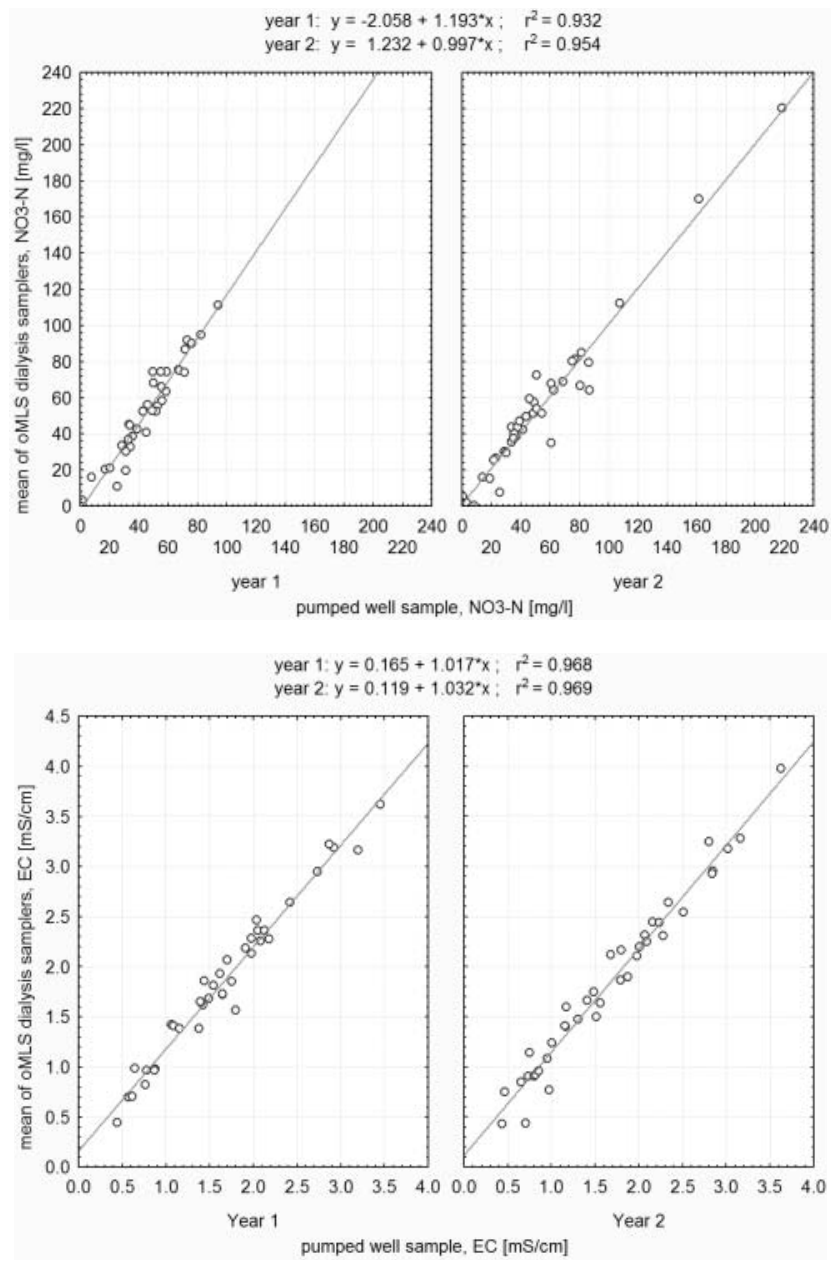

Figure 3. Regression of mean oMLS dialysis sampler concentrations (composite value, $y$-axis) against concentration of pumped well sample. Nitrate-N data are shown at top, EC data at bottom, year 1 data at left, year 2 data at right. Regression equations and $\mathbf{r}^{2}$ values appear above the respective panels. 


\section{EC Profiles}

In $\sim 27.5 \%$ of the sample profiles, the profile was nonmonotonic; that is, the center value was either higher or lower (by at least 5\%) than both the top and bottom values (Figure 4). Another $24.2 \%$ had density-stable salinity profiles with depth-increasing concentration. Salinity differences of up to $47 \%$ were observed within individual oMLS profiles. Only one EC sample set had a salinity decrease with depth; however, the difference was $<10 \%$ or $0.14 \mathrm{mS} / \mathrm{cm}$ between the top and bottom of the well, and the difference did not persist into the second year. The remaining nearly half of the oMLS samples appeared to be well mixed with respect to salinity. The data indicate that salinity gradients within the monitoring wells are usually density stable; i.e., salinity is uniform or increases with depth within the water column of the monitoring well.

\section{Nitrate- $N$ Profiles}

Only $20 \%$ of the nitrate-N profiles were thoroughly mixed along the well profile (Figure 4). Most of those specific profiles (90\%) occurred in wells, where salinity was also well mixed across the profile. Eight samples $(\sim 10 \%)$ had a nitrate profile that decreased with depth. In those cases, the maximum concentration difference within a profile averaged $6 \mathrm{mg} / \mathrm{L}$ and did not exceed $17 \mathrm{mg} / \mathrm{L}$. The minimum or maximum concentration in the center sample at levels that were significantly different from either the top or the bottom (nonmonotonic profiles) were found in $36.0 \%$ of the samples. The remaining $33.9 \%$ of the profiles were characterized by depth-increasing nitrate- $\mathrm{N}$ concentration, although only half of those profiles (or 17\% of all samples) coincided with depth-increasing salinity profiles (Table 1 ).

Maximum concentration differences within the group of depth-increasing $\mathrm{NO}_{3}-\mathrm{N}$ profiles averaged $22 \mathrm{mg} / \mathrm{L}$ and were
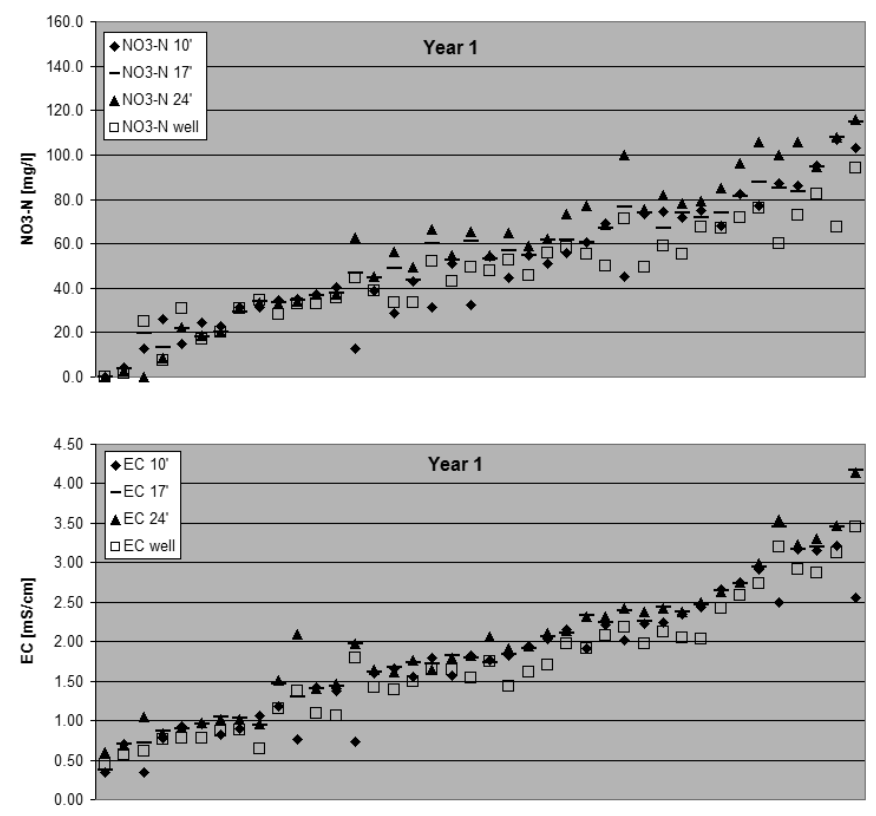

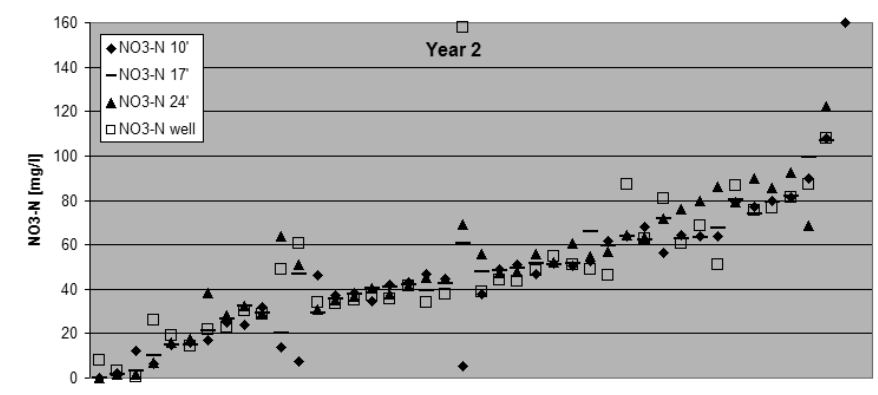

as large as 45 to $60 \mathrm{mg} / \mathrm{L}$ (Figure 4). We also found that the differences between the average dialysis sampler profile concentrations and those observed in the pumped samples did not show any significant correlations with the profile behavior. For example, for those wells with either well-mixed profiles or profiles that had decreasing $\mathrm{NO}_{3}-\mathrm{N}$ with depth, the geometric mean absolute difference between mean dialysis sampler profile $\mathrm{NO}_{3}-\mathrm{N}$ and pumped well sample $\mathrm{NO}_{3}-\mathrm{N}$ was $5.9 \mathrm{mg} / \mathrm{L}$. It was $5.2 \mathrm{mg} / \mathrm{L}$ for all other profiles. In the case of EC, the difference was somewhat larger -0.20 and 0.13 $\mathrm{mS} / \mathrm{cm}$, respectively.

Other than indicating significant nonuniformity, the data from the oMLS setup do not permit any inference on the in situ profiles in the native aquifer formation. It is possible that the measured nitrate- $\mathrm{N}$ and salinity profile correspond to similar profiles in the formation. The fact that only densitystable salinity profiles are found is to be expected. The experimental design does not tell us whether those wells with observed gradients are limited to locations where similar (density-stable) gradients exist in the formation outside the well. In those monitoring wells that are located in a formation with a significant inverse density gradient, higher salinity (higher density) water entering near the top of the screen would likely migrate within the open casing or screen toward the bottom of the well. Inverse density gradients in the formation may occur, e.g., after applications of manure-laden irrigation water, which may have significantly higher salinity than ground water. Whether the density adjustment in the well casing is laminar or leads to turbulent mixing is not evident from our data.

While nonuniform concentrations and significant water quality differences appeared to be common in the monitoring well profiles at this site, the $2.1 \mathrm{~m}$ vertical spacing between samplers was an adequate vertical sampling frequency to

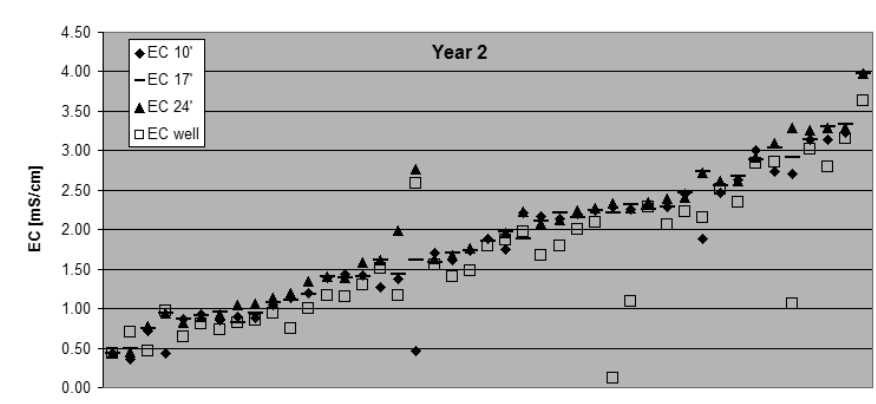

Figure 4. Comparison of the concentration profile obtained from the three oMLS dialysis membrane samplers at 10,17 , and $24 \mathrm{ft}$ $(3,5.1$, and $7.2 \mathrm{~m}$, respectively) depth with the pumped well sample concentration (well). Nitrate-N data are shown at top, EC data at bottom, year 1 data at left, year 2 data at right. Each vertical quadruplet of symbols belongs to the same well. Nitrate-N data above $160 \mathrm{mg} / \mathrm{L}$ are not shown. 


\begin{tabular}{|c|c|c|c|c|c|c|}
\hline \multicolumn{7}{|c|}{$\begin{array}{c}\text { Table } 1 \\
\text { Statistical Occurrence of Specific Nitrate and EC Concentration Profiles }\end{array}$} \\
\hline Profile Description & Year 1 & $\begin{array}{c}\text { Nitrate- } \\
\text { Year } 2\end{array}$ & Average & Year 1 & $\begin{array}{c}\text { EC } \\
\text { Year } 2\end{array}$ & Average \\
\hline $\begin{array}{l}\text { Profile is in order (middle value is in } \\
\text { between top and bottom value) }\end{array}$ & $60.5 \%$ & $67.5 \%$ & $64.0 \%$ & $67.4 \%$ & $77.5 \%$ & $72.5 \%$ \\
\hline Top > bottom & $23.3 \%$ & $15.0 \%$ & $19.1 \%$ & $0.0 \%$ & $5.0 \%$ & $2.5 \%$ \\
\hline Top $=$ bottom & $25.6 \%$ & $25.0 \%$ & $25.3 \%$ & $58.1 \%$ & $47.5 \%$ & $52.8 \%$ \\
\hline Top $\geq$ bottom and in order & $48.8 \%$ & $40.0 \%$ & $44.4 \%$ & $58.1 \%$ & $52.5 \%$ & $55.3 \%$ \\
\hline Top $<$ bottom & $51.2 \%$ & $60.0 \%$ & $55.6 \%$ & $41.9 \%$ & $47.5 \%$ & $44.7 \%$ \\
\hline Top > bottom and in order & $11.6 \%$ & $7.5 \%$ & $9.6 \%$ & $0.0 \%$ & $2.5 \%$ & $1.3 \%$ \\
\hline Top $=$ bottom and in order & $18.6 \%$ & $22.5 \%$ & $20.6 \%$ & $46.5 \%$ & $47.5 \%$ & $47.0 \%$ \\
\hline Top $\geq$ bottom and in order & $30.2 \%$ & $30.0 \%$ & $30.1 \%$ & $46.5 \%$ & $50.0 \%$ & $48.3 \%$ \\
\hline Top $<$ bottom and in order & $30.2 \%$ & $37.5 \%$ & $33.9 \%$ & $20.9 \%$ & $27.5 \%$ & $24.2 \%$ \\
\hline $\begin{array}{l}\text { Maximum concentration difference } \\
\text { if top } \geq \text { bottom and in order }\end{array}$ & 3.29 & 2.68 & 2.98 & 0.07 & 0.05 & 0.06 \\
\hline $\begin{array}{l}\text { Maximum concentration difference } \\
\text { if not (top } \geq \text { bottom and in order) }\end{array}$ & 15.25 & 16.67 & 15.96 & 0.35 & 0.47 & 0.41 \\
\hline
\end{tabular}

provide a composite (averaged) $\mathrm{EC}$ and $\mathrm{NO}_{3}-\mathrm{N}$ concentration that is within $10 \%$ of the regularly measured well concentration. The $2.1 \mathrm{~m}$ spacing is similar to the $1.5 \mathrm{~m}$ spacing recommended by the ITRC dialysis sampler workgroup (www.itrcweb.org) for sampling VOCs with LPDE dialysis samplers.

\section{Cost and Comparison to Other Sampling Methods}

One of the main advantages of the regenerated cellulose membrane sample is its low cost and simple handling. The cost of 120 oMLS samplers (sufficient to simultaneously sample 40 wells) is approximately $\$ 50$ for cage materials and $\$ 120$ for disposable materials (membrane bags) (or $\$ 0.40$ per sampler in initial hardware investment and $\$ 1$ per sampler in disposable material). For the oMLS design, the cost of disposable materials, as well as analytical cost, can be drastically reduced by constructing shorter membrane bags ( 5 to $10 \mathrm{~cm}$ length — cost $\$ 0.20$ to $\$ 0.40$ per sampler) and by combining all samples of the oMLS string into a single composite sample prior to analysis. Cage materials are commonly available at hardware stores. Cellulose membranes (e.g., Spectrapor ${ }^{\circledR}$, Cellu-Sep ${ }^{\circledR}$, Membra-Cel $\left.{ }^{\circledR \varpi}\right)$ can be ordered from medical/scientific suppliers or via the Internet.

Similarly inexpensive ground water sampling methods are bailers ( $\$ 50$ to $\$ 200)$ and car battery-operated suction-lift or submersible pumps ( $\$ 100$ to $\$ 300$ ). Bailers require a significant amount of physical work, particularly in long $5.1 \mathrm{~cm}$ monitoring wells (to remove the required 3 well volumes of stagnant water) and in wells with a deep water table. Inexpensive suction-lift and peristaltic pumps for small diameter wells are limited to use in very shallow ground water (total lift $7 \mathrm{~m}$ ). Submersible pumps, bladder pumps, and others are significantly more expensive. At heavily contaminated sites, disposal of purge water produced by bailing or pumping may be problematic and expensive. The oMLS samplers require little physical work, they can be deployed in locations with a deep water table, and they fit into small diameter monitoring wells. A key requirement, however, is that the wellbore experiences sufficient flow-through of native ground water. Since the deployment time is limited to $\sim 4 \mathrm{~d}$, linear ground water velocities through the wellbore must be on the order of at least $0.1 \mathrm{~m} / \mathrm{d}$.

A potentially major disadvantage of dialysis samplers is that they require two trips per well—one for deployment and one for removal, particularly when using regenerated cellulose membrane bags, which are subject to biodegradation. In addition, when using dialysis membranes to sample trace metals or other constituents at low concentrations, more stringent cleaning procedures may be needed to remove trace contamination within the manufactured membrane tubing (Ehlke et al. 2004). This could limit their application by nontechnical users (homeowners, farmers), unless they purchase precleaned membranes available from some manufacturers.

\section{Conclusions}

We show that dialysis membrane samplers with regenerated cellulose membranes can be used across a wide range of ground water salinity, even at elevated ground water temperatures, without being compromised by membrane biodegradation. Samplers can be emplaced in warm $\left(21^{\circ} \mathrm{C}\right)$ ground water monitoring wells with sufficient ground water flowthrough for up to $4 \mathrm{~d}$ to allow for diffusional equilibration with the naturally occurring water in the well casing. Equilibration times are $<1 \mathrm{~d}$, indicating that the cellulose membrane diffusion coefficients for salinity and nitrate are on the order of $6 \times 10^{-8}$ to $10^{-7} \mathrm{~cm}^{2} / \mathrm{s}$ or higher. We applied the dialysis sampler in an oMLS procedure to test water quality immediately below the shallow water table in an alluvial aquifer impacted by land application of animal manure and fertilizer application. Results show that large salinity and, in particular, nitrate contrasts can exist even over relatively 
short $(7 \mathrm{~m})$ vertical distances within the screened portion of a monitoring wellbore. While most wells showed relatively uniform salinity distribution, $80 \%$ of the observed wells had nonuniform nitrate distributions. Despite the vertical nonuniformity, the use of three or more membrane bags placed in an oMLS configuration along the monitoring well screen at distances of $\sim 1.5$ to $2 \mathrm{~m}$ provides results comparable (within $10 \%$ ) to those obtained by purging and sampling the same monitoring well with a standard pump or bailer system. The use of the oMLS setup with membrane samplers is an inexpensive well sampling alternative where the use of pumps or bailers is either not desirable or possible. Samples from multiple samplers along the well screen can be combined (composite sample) to lower analytical cost. The oMLS design is useful to detect potential concentration gradients in monitoring wells, although formation specific profiles are only obtained with a multilevel sampling arrangement that prohibits the vertical exchange of water within the well casing (Ronen et al. 1986; Ronen et al. 1987).

\section{Acknowledgments}

Funding for this research was provided by the California Dairy Research Foundation and the University of California Sustainable Agriculture Research and Education Program. We would like to thank Marsha Campbell Mathews for coordinating the irrigation management with our well sampling, and Rigo Rios for his technical support. The constructive reviews provided by Theodore Ehlke and Craig Divine greatly improved the quality of this manuscript.

Editor's Note: The use of brand names in peer-reviewed papers is for identification purposes only and does not constitute endorsement by the authors, their employers, or the National Ground Water Association.

\section{References}

Brandl, H., and K.W. Hanselmann. 1991. Evaluation and application of dialysis porewater samplers for microbiological studies at sediment-water interfaces. Aquatic Sciences 53, 55-73.

Carlson, R.M. 1978. Automated separation and conductimetric determination of ammonia and dissolved carbon dioxide. Analytical Chemistry 50, 1528-1531.

Chapman, D. 2000. The virtual fish: SPMD (semi-permeable membrane device) basics, http://wwwaux.cerc.cr.usgs.gov/ SPMD/index.htm.

Dasika, R., and J. Atwater. 1995. Groundwater nitrate profiling by passive sampling over extended depth beneath the water table: A demonstration. Water Research 29, no. 11: 2609-2612.

Davison, W., G. Fones, M. Harper, P. Teasdale, and H. Zhang. 2000. Dialysis, DET, and DGT: In situ diffusional techniques for studying water, sediments and soils. In In Situ Monitoring of Aquatic Systems: Chemical Analysis and Speciation, ed. J. Buffle and G. Horvai. New York: Wiley.

Divine, C.E., and J.E. McCray. 2004. Estimation of membrane diffusion coefficients and equilibration times for low-density polyethylene passive diffusion samplers. Environmental Science \& Technology 38, 1849-1857.

Ehlke, T.A., T.E. Imbrigiotta, and J.M. Dale. 2004. Laboratory comparison of polyethylene and dialysis membrane diffusion samplers. Ground Water Monitoring \& Remediation 24, no. 1: 53-59.

Harper, M.P., W. Davison, and W. Tych. 1997. Temporal, spatial, and resolution constraints for in situ sampling device using diffusional equilibration: Dialysis and DET. Environmental Science \& Technology 31, 3110-3119.

Harter, T., H. Davis, M.C. Mathews, and R.D. Meyer. 2002. Shallow groundwater quality on dairy farms with irrigated forage crops. Journal of Contaminant Hydrology 55, 287-315.

Hesslein, R.H. 1976. An in situ sampler for close interval pore water studies. Limnology and Oceanography 21, no. 6: 912 914.

Kaplan, E., S. Banerjee, D. Ronen, M. Magaritz, A. Machlin, M. Sosnow, and E. Koglin. 1991. Multilayer sampling in the water table region of a sandy aquifer. Ground Water 29, no. 2: 191198.

Peiffer, S., K. Walton-Day, and D.L. Macaldy. 1999. The interaction of natural organic matter with iron in a wetland receiving acid mine drainage. Aquatic Geochemistry 5, 207-223.

Prest, H.F., L.A. Jacobson, and J.N. Huckins. 1995. Passive sampling of water and coastal air via semipermeable membrane devices. Chemosphere 30, no. 7: 1351-1361.

Rettinger, S., D. Ronen, A.J. Amiel, M. Magaritz, and W. Bischofsberger. 1991. Tracing the influx of sewage from a leaky sewer into a very thin and fast-flowing aquifer. Water Research 25, 75-81.

Ronen, D., M. Magaritz, and F.J. Molz. 1991. Comparison between natural and forced gradient tests to determine the vertical distribution of horizontal transport properties in aquifers. Water Resources Research 27, no. 6: 1309-1314.

Ronen, D., M. Magaritz, and I. Levy. 1986. A multi-layer sampler for the study of detailed hydrochemical profiles in groundwater. Water Research 20, 311-315.

Ronen, D., M. Magaritz, H. Gvirtzman, and W. Garner, 1987. Microscale chemical heterogeneity in groundwater. Journal of Hydrology 92, 173-178.

Sanford, W.E., R.G. Shropshire, and D.K. Solomon. 1996. Dissolved gas tracers in groundwater: Injection, sampling, and analysis. Water Resources Research 32, no. 6: 1635-1642.

Södergren, A. 1987. Solvent-filled dialysis membranes simulate uptake of pollutants by aquatic organisms. Environmental Science \& Technology 21, 855-863.

U.S. Air Force. 2003. Final comprehensive results report for the passive diffusion bag sampler demonstration. Air Force Center for Environmental Excellence-Science and Engineering Division and Air Force Environmental Directorate and Air Force Real Property Agency and Defence Logistics Agency Contract F41624-00-D-8024, http://www.itrcweb.org.

U.S. Geological Survey. 1999. The quality of our nation's waters. Circular 1225, http://water.usgs.gov/pubs/circ/circ1225/.

Vroblesky, D.A. 2001. User's guide for polyethylene-based passive diffusion bag samplers to obtain volatile organic compound concentration in wells, Part 1. Deployment, recovery, data interpretation, and quality control and assurance. U.S. Geological Survey Water Resources Investigations Report 01-4060.

Vroblesky, D.A., and W.T. Hyde. 1997. Diffusion samplers as an inexpensive approach to monitoring VOCs in ground water. Ground Water Monitoring \& Remediation 17, no. 3: 177-184.

Weisbrod, N., D. Ronen, and R. Nativ. 1996. New method for sampling groundwater colloids under natural gradient flow conditions. Environmental Science \& Technology 30, no. 10: 30943101. 


\section{Biographical Sketches}

Thomas Harter, corresponding author, is currently associate cooperative extension specialist in subsurface hydrology and a faculty member of the Department of Land, Air, and Water Resources at the University of California, Davis. He received a Ph.D. in hydrology from the University of Arizona, where he also was a Fulbright Scholar and Harshbarger Fellow. He earned an M.S. in physical geography/hydrology from the Universities of Freiburg and Stuttgart, Germany. Harter is conducting research on deep vadose zone characterization and ground water resources assessment through ground water flow and contaminant transport modeling. He has also taught numerous courses and workshops on topics including ground water flow and transport modeling, vadose zone modeling, and applied ground water hydrology.

Samer Talozi is currently assistant professor in biosystems engineering at the Jordan University of Science and Technology in Irbid, Jordan. He recently received a Ph.D. in biological and agricultural engineering from the University of California, Davis. 